\title{
Impact of influenza across 27 public emergency departments in Australia: a 5-year descriptive study
}

\author{
Justin Boyle, ${ }^{1}$ Julia Crilly, ${ }^{2,3}$ Gerben Keijzers, ${ }^{4,5}$ Marianne Wallis, ${ }^{3}$ James Lind, \\ Ross Sparks, ${ }^{6}$ Louise Ryan ${ }^{6}$
}

${ }^{1}$ CSIRO Information and Communication Technologies Centre, Brisbane, Australia

${ }^{2}$ Statewide Emergency Department Clinical Network, Queensland Health, Queensland, Australia

${ }^{3}$ Research Centre for Clinical and Community Practice Innovation, Griffith University, Gold Coast, Australia ${ }^{4}$ Gold Coast Hospital Emergency Department, Queensland Health, Gold Coast, Australia ${ }^{5}$ Faculty of Health Sciences and Medicine, Bond University, Oueensland, Australia ${ }^{6}$ CSIRO Mathematics Informatics and Statistics, Sydney, Australia

Correspondence to Dr Justin Boyle, CSIRO Information and Communication Technologies Centre, Level 5, UO Health Sciences Building Royal Brisbane and Women's Hospital, Herston, 4029 , Queensland, Australia; justin.boyle@csiro.au

Accepted 19 August 2011

\section{ABSTRACT}

Objective To describe the incidence, characteristics and outcomes of patients with influenza-like symptoms presenting to 27 public hospital emergency departments (EDs) in Queensland, Australia.

Methods A descriptive retrospective study covering 5 years (2005-9) of historical data from 27 hospital EDs was undertaken. State-wide hospital ED Information System data were analysed. Annual comparisons between influenza and non-influenza cases were made across the southern hemisphere influenza season (June-September) each year.

Results Influenza-related presentations increased significantly over the 5 years from $3.4 \%$ in 2005 to $9.4 \%$ in 2009 , reflecting a $276 \%$ relative increase. Differences over time regarding characteristics of patients with influenza-like symptoms, based on the influenza season, occurred for admission rate (decreased over time from $28 \%$ in 2005 to $18 \%$ in 2009), length of stay (decreased over time from a median of $210 \mathrm{~min}$ in 2005 to $164 \mathrm{~min}$ in 2009) and access block (increased over time from $33 \%$ to $41 \%)$. Also, every year there was a significantly $(p<0.001)$ higher percentage of access block in the influenza cohort than in the non-influenza cohort.

Conclusions Although there was a large increase over time in influenza-related ED presentations, most patients were discharged home from the ED. Special consideration of health service delivery management (eg, establishing an 'influenza clinic border protection and public rollout of vaccination, beginning with those most at risk') for this group of patients is warranted but requires evaluation. These results may inform planning for service delivery models during the influenza season.

\section{INTRODUCTION}

Novel influenza-like illnesses such as sudden acute respiratory syndrome, avian influenza and the 2009 H1N1 influenza have presented as an ongoing global threat over the last 5 years. ${ }^{1-6}$ The impact of these illnesses on a local community can be widespread. Medical consumption increases, mainly for primary care providers (general practitioners and emergency departments (EDs)), leading to isolation/infection control decisions. The impact of higher ED presentations may have an effect on patient ED and length of stay (LOS) (defined as the difference between arrival time and departure time $)^{7}$ and access block (defined as the proportion of admissions with total time in the ED longer than $8 \mathrm{~h}) .^{7}$ Global overcrowding of EDs has exacerbated the incidence of access block, and several studies have documented that impaired function of the ED results in less favourable outcomes for patients, ${ }^{8-11}$ including increased mortality.

Despite WHO recommendations in managing influenza, the rate of transmission from person to person and also from country to country is rapid. The impact of influenza on hospital systems has been described in terms of triage for prioritising care (public health considerations of infectiousness should be part of standard triage assessments), ${ }^{12}$ staffing levels (high staff absentee rates should be anticipated during pandemics $)^{13}$ and clinical predictors of influenza status to support isolation decisions. ${ }^{14}$ What has not been presented in the literature, as far as we are aware, is an analysis of influenza presentations across a number of hospital sites within the southern hemisphere.

It is important to describe ED trends and historical data in health-related outcomes that can be used to inform epidemic planning as well as regular influenza season planning. This paper presents a description of the incidence of $\mathrm{ED}$ presentations, subsequent hospital admissions, as well as characteristics and outcomes of patients presenting with influenza-like illnesses over the southern hemisphere influenza season (JuneSeptember) for the 5 years from 2005 to 2009.

\section{METHODS}

\section{Study design and setting}

This retrospective descriptive study was undertaken in Queensland, one of the eight states and territories of Australia. It has a population of 4.5 million and an annual public hospital ED presentation rate of $345 / 1000$ weighted population. ${ }^{15}$ The information provided in this paper relates to presentations to 27 public hospitals that provide routinely reported data (such as waiting times and triage categories) to state and national health agencies. All included EDs have $>15000$ patients presenting annually and the hospital bed numbers range in size from 69 to 1047 . The influenza season was defined as June-September, as typically the majority of reported cases occur during this period. ${ }^{16}$ For the study data, the percentage of annual cases that occurred between June and September ranged from $34 \%$ in 2005 to $46 \%$ in 2007.

For the purposes of this study the following definitions and data groupings were used

Influenza-like cases are defined using the International Classification of Diseases (ICD-10 coding) to identify patient records with influenza-like symptoms. ICD is the international standard diagnostic classification for epidemiological, health management purposes and clinical use. They were 
defined using the following 11 ICD codes: A08.4-Viral Gastroenteritis, B34.9-Viral Infection, J10.8 (Influenza old code), J11.1 (Influenza new code), J11.1S-H1N1 Influenza (Human Swine Influenza) suspected, J18.0-Bronchopneumonia, J18.1-Lobar Pneumonia Unspecified, J18.2-Hypostatic Pneumonia Unspecified, J18.8-Pneumonia-Atypical, J18.9-Pneumonia-Unspecified, Z04.8-Medical Review.

Automatic swab analysis to confirm pathology is not routine ED practice in Queensland, hence the inclusion of these codes comprising possible cases, based on clinician experience. While laboratory-confirmed cases reported to surveillance systems are recognised as one indicator of influenza activity, such laboratory data for Queensland would not comprise all cases. The specified ICD list was chosen in consultation with clinicians working at some of the participating hospitals. Although the definition covers a broad set of conditions (low specificity), it is adequate to reliably capture the diagnoses that a patient presenting with influenza might be likely to receive.

All patients presenting to an Australian ED are triaged using the Australasian Triage Scale (ATS) which comprises five categories. ${ }^{17}$ These categories range from patients who require resuscitation (ATS 1 and should be seen immediately) to patients whose medical needs are not urgent (ATS 5 and should be seen within $2 \mathrm{~h}$ of arrival at the ED).

The age brackets used when assessing age-related differences were chosen in accordance with those used by Australia's National Health and Welfare Statistics and Information Agency $(\mathrm{AIHW})^{18}$ of $0-15,16-24,25-64,65+$ brackets, which are useful clinically-that is, children, young adults, adults and older people. The youngest age bracket was further split $(0-5$, $6-10,11-15$ years) as clinical advice indicates possible differences between them, particularly regarding the $2009 \mathrm{H} 1 \mathrm{~N} 1$ influenza vaccine which was not offered to those aged $<10$ years until 3 December 2009. ${ }^{19}$

The data were cleaned to exclude cases of unknown gender, age $>104$ years (a known age wild card), and LOS in the ED $>8000 \mathrm{~min}$ (based on assessing the LOS frequency distribution).

\section{Data analysis}

Data were stored and collated using Microsoft Office Excel (V.2007 2006, Microsoft Corporation). Descriptive and inferential statistics were performed. Descriptive statistics, presented as mean $( \pm S D)$ and median (Md) (IOR) were used to explore the patient characteristics (such as age) and outcome measures (ED LOS) between the groups (influenza or non-influenza) and years. Frequency distributions were used for binary categorical outcome variables of ED LOS ( $>8 \mathrm{~h}$ ) and hospital mortality. Inferential statistics were used to identify differences between groups (influenza or non-influenza) and between years. $t$ Tests were used for normally distributed data, the Mann-Whitney $U$ test for non-normally distributed data and $\chi^{2}$ tests for categorical variables. One-way ANOVA was used for comparisons across multiple years. Two-tailed tests were used and a level of significance was set at $\mathrm{p}<0.05$ with $95 \%$ confidence limits. SPSS V.17.0 was used for these data analyses. Analysis of variance tests were performed using Matlab (V.7.2.0.232 R2006a, The MathWorks Inc).

\section{RESULTS}

There were approximately 1.7 million ED presentations in Queensland public hospitals in the 2005-9 southern hemisphere influenza seasons (June-September). Influenza and non-influenza presentations and subsequent admissions across the
2005-9 influenza seasons are shown in table 1. In every year the influenza cohort differed significantly $(p<0.001)$ from the noninfluenza cohort in every characteristic apart from gender of hospital admissions. Influenza-related presentations increased significantly over the 5 years from $3.4 \%$ in 2005 to $9.4 \%$ in 2009 , reflecting a $276 \%$ relative increase. This increase occurred in the presence of increasing growth in patient presentations $36 \%$ across the 5 years), which was well beyond official population growth (10\% over 5 years). ${ }^{20}$ This finding was reproduced for patients who were admitted-influenza admissions increased from $4.3 \%$ in 2005 to $7.6 \%$ in 2009 (176\% relative increase) in the presence of increasing growth in hospital admissions $(38 \%$ across the 5 years). Figure 1 shows mean growth rates across the study period, generated from assessing changes between consecutive years.

Figure 2 shows the trends in influenza presentations and admissions in terms of patient numbers and timing. The trend in patient numbers was generally stable from 2005 to 2007, followed by a small fall in 2008 before a peak in 2009. There was a strongly significant $(p<0.001)$ increase in both influenza presentations and influenza hospital admissions in 2009 as well as an earlier peak of presentations in the influenza season.

Further differences between influenza seasons and influenza/ non-influenza patient cohorts are explored in terms of age, triage category (ATS), diagnosis, admission rate, LOS and access block.

\section{Age}

For every year in the study period, patients presenting with influenza symptoms were significantly younger than the noninfluenza cohort (mean 27.4 vs 34.8 years, $p<0.001$ ). The mean age of influenza presentations increased from 25.5 years $(95 \% \mathrm{CI}$ 25.1 to 25.9 ) in 2007 to 26.2 years ( $95 \%$ CI 25.8 to 26.6 ) in 2008 , to 27.9 (95\% CI 27.6 to 28.2 ) in 2009 . Over the 5 -year study period, admitted patients with influenza tended to be younger than patients without influenza, although this was not significantly different (mean 45.3 vs 47.5 years, $p=0.06$ ).

Although the $0-5$ age bracket contributes only around $8 \%$ of the Queensland patient population, interestingly, this patient group contributes significantly more $(p<0.001)$ to ED presentations and subsequent admissions to hospital, and particularly more so when diagnosed with influenza-like symptoms. While there are proportionately significantly $(p<0.001)$ more patients aged $0-5$ years in the influenza cohort than in the non-influenza cohort, it can be seen that, for 2009, the proportion of patients with influenza aged $0-5$ years (presentations) decreased significantly $(p<0.001)$ compared with previous years. Conversely, the proportions of the 16-24 and 25-64 age brackets increased significantly $(p<0.001)$ in 2009 . This is particularly interesting considering the significant increases in influenza presentations and ED admissions in 2009.

\section{Triage category/urgency}

For all years, influenza presentations had a significantly $(p<0.001)$ lower proportion of ATS 1 and 2 (most urgent) patients than non-influenza presentations. Influenza admissions also had significantly $(p<0.001)$ lower proportions of ATS 1 and 2 than the non-influenza admitted cohort, suggesting lower urgency of influenza patients compared with the non-influenza cohort. However, the criticality/triage levels of admitted patients were not significantly different proportionally in 2009 $(\mathrm{p}=0.2)$.

\section{Diagnosis}

Viral infections (B34.9) comprise most of the 'influenza' presentations, yet pneumonia diagnoses dominate the 


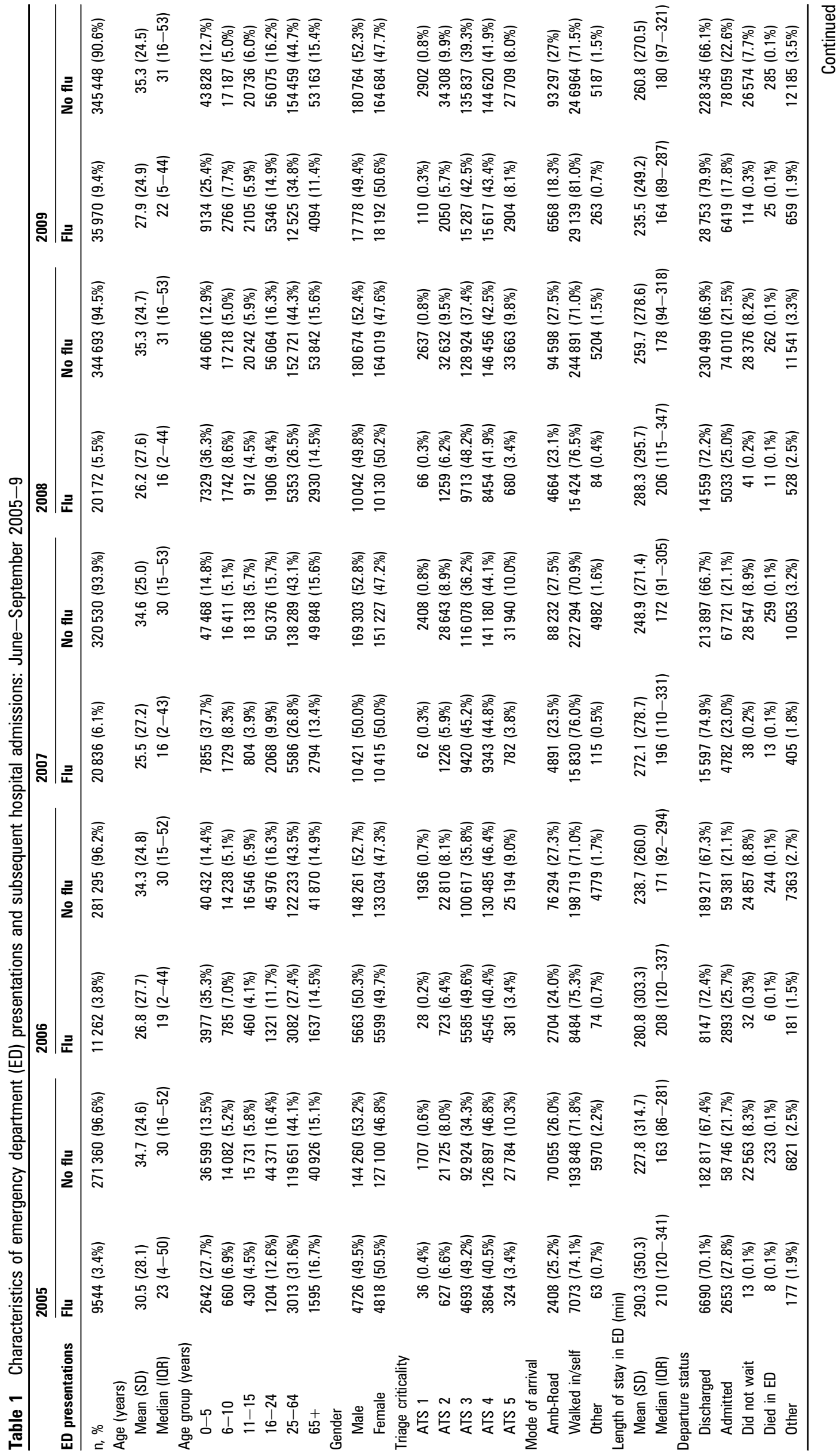




\section{Original article}

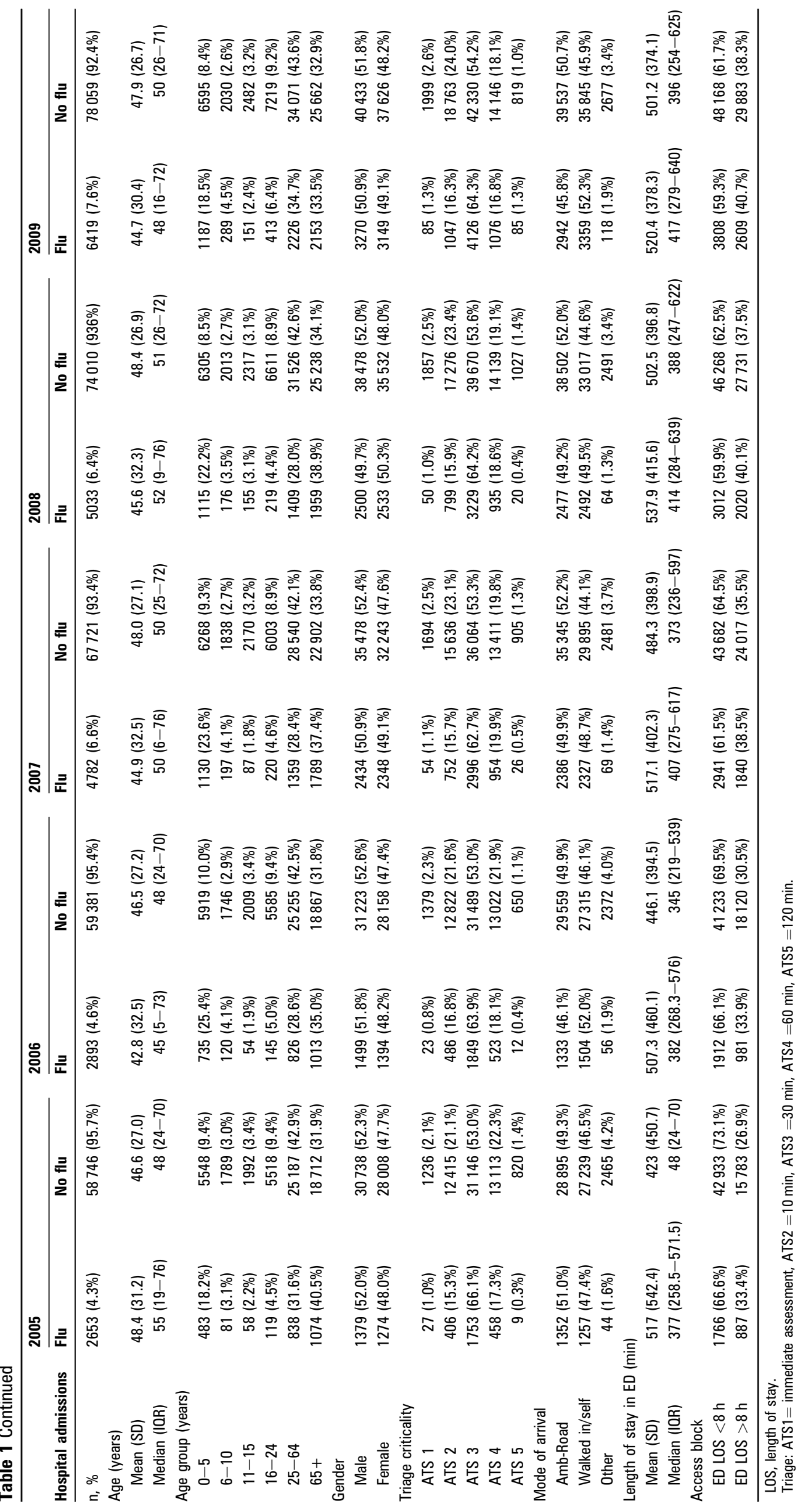




\section{Mean annual growth rate 2006-2009 (Mean \& 95\% Cl)}

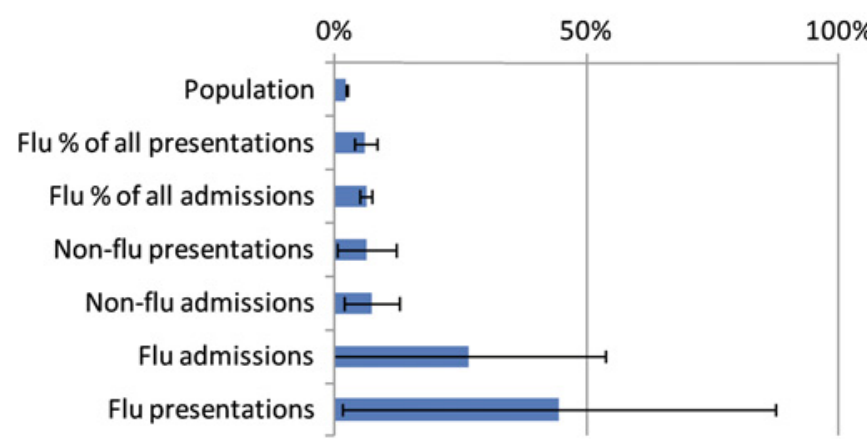

Figure 1 Relative changes in emergency department characteristics over the study period.

'influenza' hospital admissions. Previous years also show negligible influenza (J10.8, J11.1, J11.1S) diagnoses which appear in the 2009 data. It should be remembered that the overall scale of these cases is small (approximately 1\% of the state population).

\section{Departure/disposition status and influenza admission rate}

Between 2005 and 2008 the proportion of patients admitted with influenza was significantly higher compared with the admitted non-influenza patient cohort $(25.3 \%$ vs $21.3 \%$, $\mathrm{p}<0.001)$ but in 2009 it was significantly lower $(17.8 \%$ vs $22.6 \%$, $p<0.001)$. While there were significantly higher numbers of patients admitted with influenza in 2009 compared with previous years $(p<0.001)$, the admission rate for influenza patients (percentage of influenza presentations that were admitted) decreased over the study period from $28 \%$ in 2005 to
$18 \%$ in 2009. The admission rate in 2009 for influenza was significantly less than in previous years $(p<0.001)$ while the admission rate for the non-influenza cohort was fairly constant at $22 \%$. Patients who died in the ED remained constant every year at $0.1 \%$ for both the influenza and non-influenza patient cohorts.

\section{ED LOS and access block}

Between 2005 and 2008, patients with influenza experienced significantly longer $(p<0.001)$ stays in the ED than the noninfluenza patient cohort (figure 3A). In 2009, however, ED LOS was significantly shorter for patients with influenza than for the non-influenza cohort (236 min vs $261 \mathrm{~min}, \mathrm{p}<0.001)$. For patients with influenza who were admitted, however, the ED LOS was significantly longer than for the non-influenza admitted cohort (eg, $520 \mathrm{~min}$ vs $501 \mathrm{~min}$ in 2009).

Across the study period, each year there were more patients whose LOS exceeded $8 \mathrm{~h}$ (access-blocked patients) than the preceding year (figure $3 \mathrm{~B}$ ). For influenza patients the proportion of access-blocked patients increased from $33.4 \%$ in 2005 ( $n=887$ ) to $40.7 \%$ in 2009 ( $n=2609)$, representing a $122 \%$ proportional increase (and an almost 300\% increase in access-blocked patient numbers). For non-influenza patients, the proportional increase was $142 \%$ with a $190 \%$ increase in access-blocked patients. Also every year there was a significantly $(p<0.001)$ higher percentage of access block in the influenza cohort than in the non-influenza cohort.

\section{DISCUSSION}

From our data it is evident that influenza presentations are increasing each year, with a dramatic increase in 2009. Confirmed cases of 2009 H1N1 influenza across June-September 2009 in Queensland have been reported previously, ${ }^{16}$ and
Flu presentations

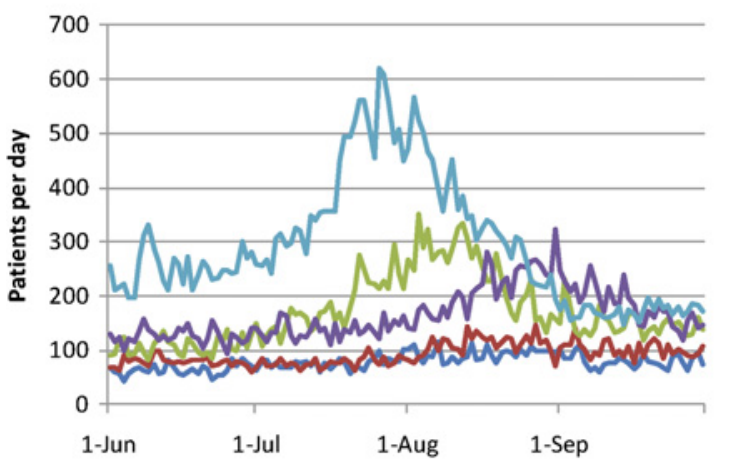

Flu presentations - Mean $\& 95 \% \mathrm{Cl}$

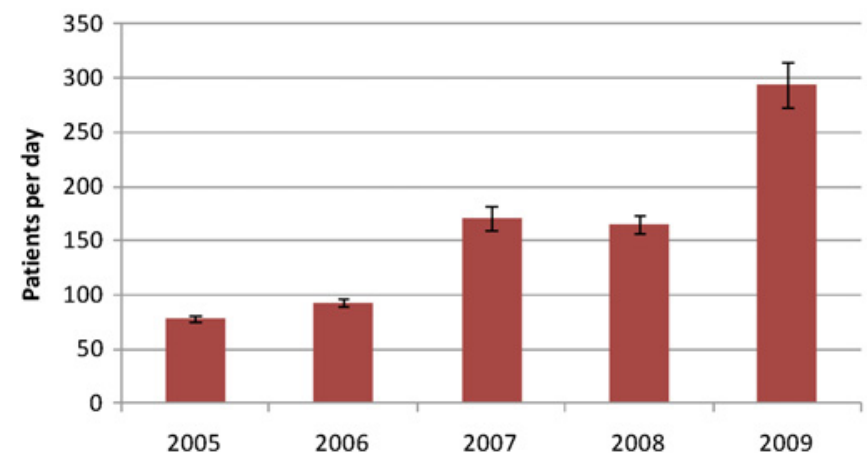

Flu admissions from ED

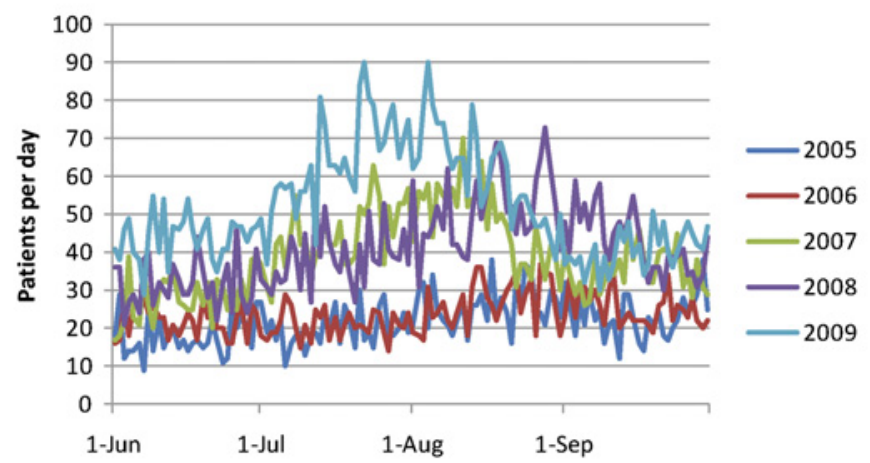

Flu admissions from ED - Mean \& 95\% Cl

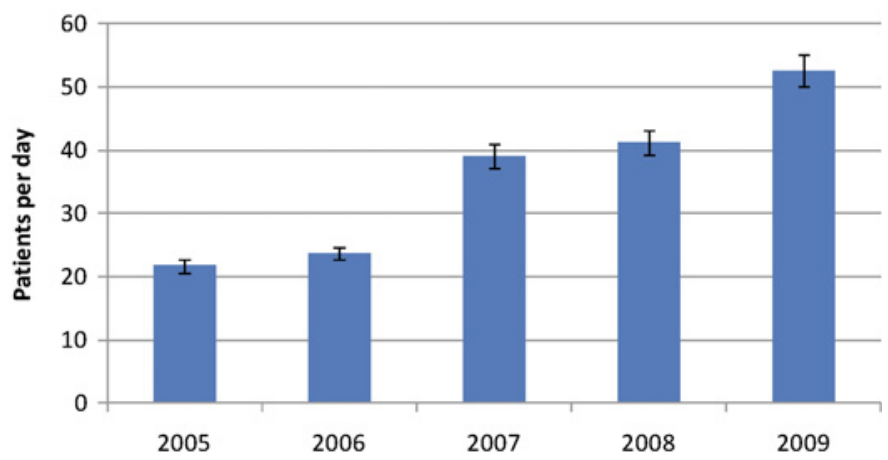

Figure 2 Influenza presentations and hospital admissions 2005-9. 
A

\section{LOS in ED - presentations \\ (Mean \& 95\% Cl)}

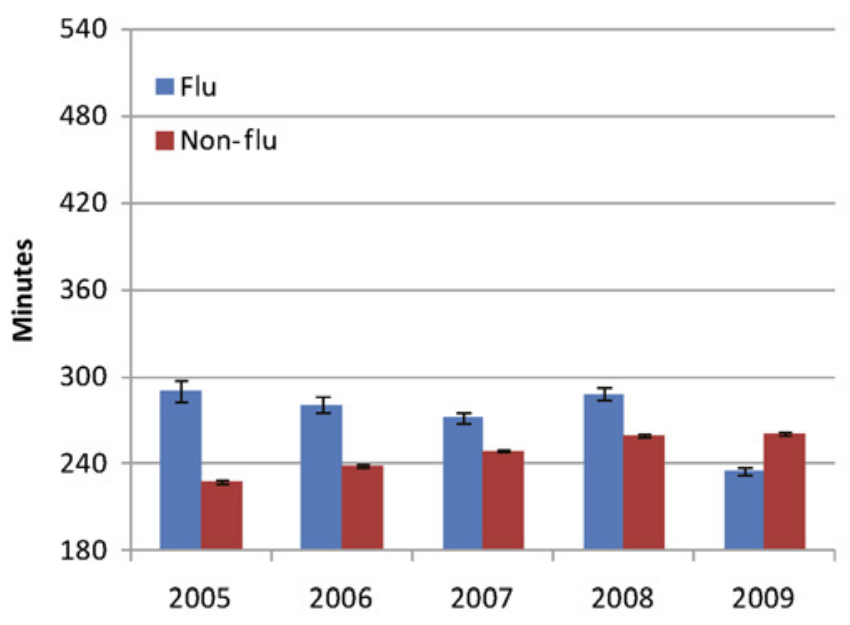

\section{LOS in ED - Admitted patients (Mean \& 95\% Cl)}

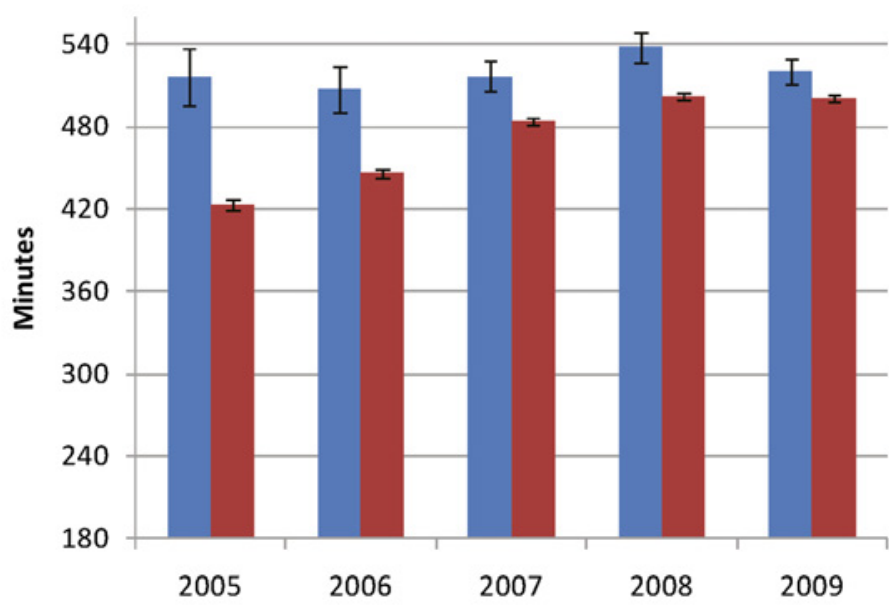

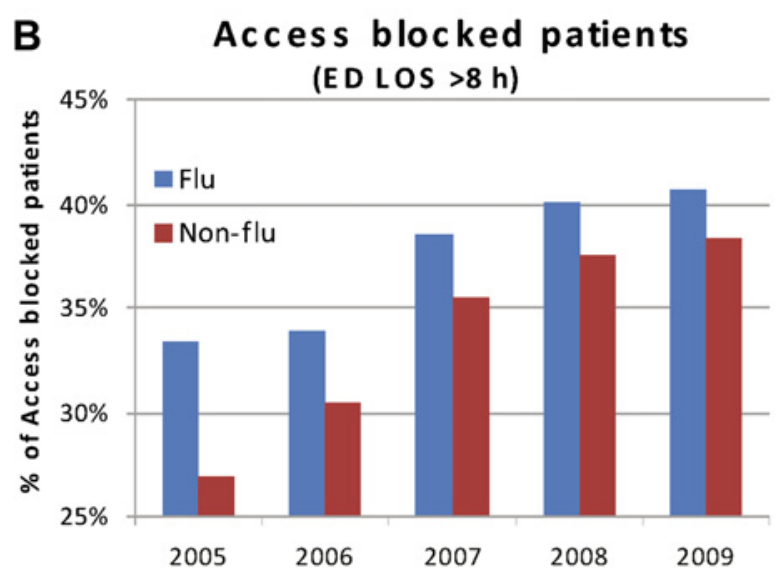

Figure 3 Changes in (A) emergency department length of stay (ED LOS) and (B) access block 2005-9.

reached a peak in mid July 2009. Our data are consistent with this and additionally show that, from 2005 to 2007, the number of influenza presentations doubled and then almost doubled again from 2007 to 2009. As populations around the world become more urbanised, influenza is going to become a major burden on the health system with potentially increased infection rates and more virulent influenza viruses.

The age results are interesting in that they suggest a more pronounced susceptibility in the 25-64 year age bracket compared with previous years, whereas in other years most influenza admissions were older patients aged $65+$ years. One possible explanation is an improved immunity of patients exposed to an influenza strain in the 1950 s. ${ }^{21}$ On a year-by-year basis, the data show that the highest influenza presentation rates were for the very young.

A previous report has indicated that the $2009 \mathrm{H} 1 \mathrm{~N} 1$ virus had a substantial effect on hospitals during the 2009 winter. ${ }^{6}$ Access block is one of several measures of hospital performance ${ }^{22}$ and has been linked to poorer health outcomes. ${ }^{8-11}$ A large proportion of patients in our study who required hospital admission had an ED LOS that exceeded $8 \mathrm{~h}$ (access-blocked patients). This increased over time from $27 \%$ in 2005 to $38 \%$ in 2009. The increase in access block was noted for both influenza and noninfluenza patient admissions across every year of the study period. It is possible that these increases in access block figures reflect broader hospital-wide system issues which were exacerbated by the 2009 H1N1 virus.

Recommendations for future research and application concern the ability to forewarn health authorities of such events. Without pandemic cycles there can be little basis for predicting pandemic emergence. ${ }^{23}$ As such, there is potential benefit in the areas of surveillance monitoring of influenza cases to signal unusual activity, generating forecasts based on historical data and using internet search data as outbreak notifications among a population. ${ }^{24}$ The authors have commenced research in this area.

Analysis of historical data can inform service delivery planning (eg, in rostering extra staff): the fact that influenza presentations have a shorter and lower urgency than noninfluenza cases could lead to the conclusion that relatively junior medical staff could handle this in a clinical setting with a higher turnover, taking away pressures from the ED.

\section{Limitations of the study}

This study has the following limitations. It focuses on the impact on public hospitals and their EDs and it was therefore outside the scope of the study to describe actual disease prevalence (ie, patients with the disease presenting to private hospitals, primary care physicians or not at all). We have not included data from general practitioners which may be considered the 
front line in diagnosis. Private hospitals do not contribute to national collection of triage data, ${ }^{15}$ hence these data were not included.

Swabbing was not undertaken to confirm influenza status and, indeed, is usually only taken for certain clinical indications such as pregnancy, patients with comorbidities and patients who are immunocompromised. It is therefore possible that the results do not reflect influenza and may instead relate to other respiratory viruses with similar characteristics to influenza. Diagnosis of influenza may have been confirmed with laboratory testing for a reasonable proportion of cases, but these data were not available to use. The diagnosis as reported was therefore assumed correct as per ICD coding of diagnosis, but this may have led to under- or over-reporting of cases. However, this would have been similar over the years and is therefore unlikely to be the cause of the observations.

Although statistically significant differences between influenza and non-influenza patients were found, some of these differences may have limited direct clinical relevance (such as 20 min differences in LOS or age differences of $1-2$ years) and so be important to observe and identify trends.

Finally, this study was carried out in one state that may be seen to have a particular demographic and climatic profile. As such, the patients may not be representative of those presenting to other EDs and may lack external validity.

\section{CONCLUSIONS}

This study shows clear trends over a large population group in the southern hemisphere. Influenza-like presentations were less urgent than non-influenza presentations, and in 2009 had a significantly shorter ED LOS as well as significantly lower hospital admission rates contrary to previous years in the study. The 2009 H1N1 influenza outbreak did represent a significant departure from the normal ED influenza workload relative to previous years and resulted in significantly more hospital admissions and an increased number of access-blocked patients.

Acknowledgements The authors acknowledge the support of Queensland Health in providing de-identified data for this research.

Funding The work was supported by funding provided by Australian State and Federal governments in relation to employment of the authors.

Competing interests $\mathrm{JB}, \mathrm{RS}$ and LR have support from CSIRO; JC, GK, MW and JL have support from Queensland Health; and MW has support from Griffith University for the submitted work. The support relates to employment and there was no role of the supporting sources in the study design, data collection, analysis and interpretation, writing of the article, or decision to submit the final manuscript for publication. There are no financial or professional relationships which pose a competing interest.

Ethics approval The Queensland Health Central Office human research ethics committee

Contributors $\mathrm{JL}$ initially conceived the study which was further developed by $\mathrm{JB}, \mathrm{JC}$, MW, GK and JL. JC cleaned the data and was responsible for developing the data table included in the manuscript (table 1). The design (comparing influenza with no-influenza cohorts) was the responsibility of JC, GK, JL and JB. Data analysis, including statistical comparisons, was performed by JC and JB. JB was responsible for drafting the initial article and MW contributed to strengthening the text with appropriate references. RS and LR were involved in reviewing important statistical content and aspects of data presentation. All authors had full access to all of the data (including statistical reports and tables) in the study and take responsibility for the integrity of the data and the accuracy of the data analysis. All authors were involved in reviewing the article and giving final approval for the version to be published.

Provenance and peer review Not commissioned; externally peer reviewed.

Data sharing statement Study data are unable to be shared.

\section{REFERENCES}

1. Taubenberger JK, Morens DM. Influenza revisited. Emerg Infect Dis 2006;12:1-2.

2. Fauci AS. Race against time. Nature 2005;435:423-4

3. Webby RJ, Webster RG. Are we ready for pandemic influenza? Science 2003:302:1519-22.

4. Webster RG, Peiris M, Chen H, et al. H5N1 outbreaks and enzootic influenza. Emerg Infect Dis 2006;12:3-8.

5. Baker M, Kelly H, Wilson N. Pandemic H1N1 influenza lessons from the southern hemisphere. Euro Surveill 2009;14:19370.

6. Webb SA, Pettilä V, Seppelt I, et al; ANZIC Influenza Investigators. Critical care services and $2009 \mathrm{H} 1 \mathrm{~N} 1$ influenza in Australia and New Zealand. N Engl J Med 2009;361:1925-34.

7. Australasian College for Emergency Medicine (ACEM). ACEM Policy on Standard Terminology. West Melbourne: ACEM, 2009. http://www.acem.org.au/ media/policies_and_guidelines/P02_-_Standard_Terminology_16.04.09.pdf (accessed Jul 2011).

8. Fatovich DM, Nagree Y, Sprivulis P. Access block causes emergency department overcrowding and ambulance diversions in Perth, Western Australia. Emerg Med $\mathrm{J}$ 2005;22:351-4.

9. Brown D. Marked increase in patients who leave the ED without treatment. Acad Emerg Med 2002;9:510.

10. Cameron PA. Hospital overcrowding: a threat to patient safety? Med J Aust 2006;184:203-4.

11. Richardson DB. Increase in patient mortality at 10 days associated with emergency department overcrowding. Med J Aust 2006;184:213-16.

12. Bradt DA, Drummond CM. Avian influenza pandemic threat and health systems response. Emerg Med Australas 2006;18:430-43.

13. Martinese F, Keijzers G, Grant S, et al. How would Australian hospital staff react to an avian influenza admission, or an influenza pandemic? Emerg Med Australas 2009;21:12-24.

14. Keijzers GB, Vossen CN, Zhang P, et al. Predicting influenza A and 2009 H1N1 influenza in patients admitted to hospital with acute respiratory illness. Emerg Med $\mathrm{J}$ 2011;28:500-6.

15. The State of Our Public Hospitals, June 2010 Report. Australian Government Department of Health and Ageing, Commonwealth of Australia, 2010. http://www. health.gov.au/ahca (accessed Jul 2011)

16. Bishop JF, Murnane MP, Owen R. Australia's winter with the 2009 pandemic influenza A (H1N1) virus. N Engl J Med 2009;361:2591-4.

17. Australasian College for Emergency Medicine (ACEM). Policy on the Australasian Triage Scale. West Melbourne: ACEM, 2006.

18. Australian Institute of Health and Welfare (AIHW). Australia's Health 2008. Cat. no. AUS 99. Canberra: AlHW, 2008.

19. Australian Government Department of Health and Ageing. Pandemic F/u Vaccine Approved for Children. http://www.health.gov.au/internet/ministers/ publishing.nst/Content/mr-yr09-nr-nr224.htm (accessed Jul 2011).

20. Australian Bureau of Statistics. 3218.0-Regional Population Growth, Australia 2008-09, publication Regional Population Growth (Cat. no. 3218.0). Canberra: Australian Bureau of Statistics, 2010.

21. Centers for Disease Control and Prevention. Serum cross-reactive antibody response to a novel influenza $A$ (H1N1) virus after vaccination with seasonal influenza vaccine. MMWR Morb Mortal Wkly Rep 2009:58:521-4.

22. Forero R, Hillman K. Access block and overcrowding: a literature review. Prepared for the Australasian College for Emergency Medicine. 2008. http://www.acem.org. au/media/media releases/Access Block Literature Review 08 Sept 3.pdf (accessed Jul 2011).

23. Morens DM, Taubenberger JK, Harvey HA, et al. The 1918 influenza pandemic: lessons for 2009 and the future. Crit Care Med 2010;38(4 Suppl):e10-20.

24. Boyle JR, Sparks RS, Keijzers GB, et al. Prediction and surveillance of influenza epidemics. Med J Aust 2011:194:S28-33. 


\section{EMJ}

\section{Impact of influenza across 27 public emergency departments in Australia: a 5-year descriptive study}

Justin Boyle, Julia Crilly, Gerben Keijzers, et al.

Emerg Med J published online October 27, 2011

doi: 10.1136/emermed-2011-200230

Updated information and services can be found at:

http://emj.bmj.com/content/early/2011/10/27/emermed-2011-200230.full.html

These include:

References This article cites 17 articles, 3 of which can be accessed free at: http://emj.bmj.com/content/early/2011/10/27/emermed-2011-200230.full.html\#ref-list-1

$\mathbf{P}<\mathbf{P} \quad$ Published online October 27, 2011 in advance of the print journal.

Email alerting Receive free email alerts when new articles cite this article. Sign up in service the box at the top right corner of the online article.

Topic Articles on similar topics can be found in the following collections

Collections

Influenza (18 articles)

TB and other respiratory infections (116 articles)

Drugs: infectious diseases (207 articles)

Vaccination / immunisation (20 articles)

Advance online articles have been peer reviewed, accepted for publication, edited and typeset, but have not not yet appeared in the paper journal. Advance online articles are citable and establish publication priority; they are indexed by PubMed from initial publication. Citations to Advance online articles must include the digital object identifier (DOIs) and date of initial publication.

To request permissions go to:

http://group.bmj.com/group/rights-licensing/permissions

To order reprints go to:

http://journals.bmj.com/cgi/reprintform

To subscribe to BMJ go to:

http://group.bmj.com/subscribe/ 


\section{Notes}

Advance online articles have been peer reviewed, accepted for publication, edited and typeset, but have not not yet appeared in the paper journal. Advance online articles are citable and establish publication priority; they are indexed by PubMed from initial publication. Citations to Advance online articles must include the digital object identifier (DOIs) and date of initial publication.

To request permissions go to:

http://group.bmj.com/group/rights-licensing/permissions

To order reprints go to:

http://journals.bmj.com/cgi/reprintform

To subscribe to BMJ go to:

http://group.bmj.com/subscribe/ 